\title{
Orlistat Reduces Proliferation and Enhances Apoptosis in Human Pancreatic Cancer Cells (PANC-1)
}

\author{
EWA SOKOLOWSKA ${ }^{1}$, MALGORZATA PRESLER $^{2}$, ELZBIETA GOYKE ${ }^{2}$, \\ RYSZARD MILCZAREK $^{1}$, JULIAN SWIERCZYNSKI ${ }^{2,3}$ and TOMASZ SLEDZINSKI ${ }^{1}$ \\ Departments of ${ }^{1}$ Pharmaceutical Biochemistry and ${ }^{2}$ Biochemistry, Medical University of Gdansk, Gdansk, Poland; \\ ${ }^{3}$ State School of Higher Vocational Education in Koszalin, Koszalin, Poland
}

\begin{abstract}
Background/aim: Pancreatic cancer is a disease with very poor prognosis, and none of currently available pharmacotherapies have proven to be efficient in this indication. The aim of this study was to analyze the expression of fatty acid synthase (FASN) gene as a potential therapeutic target in proliferating human pancreatic cancer cells (PANC-1), and verify if orlistat, originally developed as an anti-obesity drug, inhibits PANC-1 proliferation. Materials and Methods: The effects of orlistat on gene expression, lipogenesis, proliferation and apoptosis was studied in PANC-1 cell culture. Results: Expression of FASN increased during proliferation of PANC-1. Inhibition of FASN by orlistat resulted in a significant reduction of PANC-1 proliferation and enhanced apoptosis of these cells. Conclusion: This study showed, to our knowledge for the first time, that orlistat exhibits significant antitumor activity against PANC-1 cells. This implies that orlistat analogs with good oral bioavailability may find application in pharmacotherapy of pancreatic cancer.
\end{abstract}

Pancreatic cancer is a malignancy with particularly unfavorable prognosis. None of currently available chemotherapy regimens have proven to be effective in this indication, and 5-year survival rates for patients with pancreatic ductal adenocarcinoma (PDAC) are no greater than 5\% (1). This justifies extensive research on novel, more effective chemotherapeutics that would improve outcomes in this malignancy. Carcinogenesis is associated with substantial changes in cell metabolism of lipids, carbohydrates, nucleic acids and amino acids (1). These changes result in rapid proliferation of cancer cells. More

Correspondence to: Tomasz Sledzinski, Department of Pharmaceutical Biochemistry, Medical University of Gdańsk, Dębinki 1, 80-211 Gdańsk, Poland. Tel/Fax: +48 583491465, e-mail: tsledz@gumed.edu.pl

Key Words: Orlistat, pancreatic cancer, PANC-1 cells. than eight decades ago, Warburg revealed that enhanced anaerobic glycolysis, a phenomenon commonly referred to as the Warburg effect, is a distinctive feature of many human and animal cancer cells (2). During the course of glycolysis, glucose is converted into pyruvate; the latter is either reduced to lactate in cytosol or converted into acetyl-CoA, a substrate for fatty acids synthesis, in mitochondria. As a substrate for phospholipid synthesis, fatty acids are the main component of plasma membranes. The demand for these compounds increases dramatically in quickly-proliferating cancer cells. Fatty acids may also serve as a substrate for protein palmitoylation, a process that is vital for regulation of cancer cell proliferation. Therefore, not surprisingly, previous studies documented up-regulation of enzymes involved in lipid synthesis in many types of cancer, including pancreatic cancer $(1,3)$.

Fatty acid synthase (FASN) is an enzyme catalyzing synthesis of fatty acids, primarily palmitate. A key role of FASN in carcinogenesis was documented more than two decades ago, when this enzyme was identified as oncogenic antigen-519 (OA-519) in patients with breast cancer (4). FASN is the most widely studied lipogenic enzyme in pancreatic cancer. Its overexpression in pancreatic cancer cells was shown to be associated with poor prognosis (1), as well as with resistance to gemcitabine and radiotherapy (5). This implies that inhibition of FASN might be considered as a therapeutic target in patients with pancreatic cancer. This hypothesis is supported by the fact that treatment with siRNA or FASN inhibitors produced cytotoxic and cytostatic effects in various cancer cells (1). FASN inhibitors include cerulenin, epigallocatechin gallate (a component of green tea extract), luteolin and orlistat, as well as some synthetic agents (1). Antiproliferative activity of two FASN inhibitors, luteolin and C75, was recently documented in pancreatic cancer cell lines (6).

Orlistat (tetrahydrolipstatin, a synthetic derivative of lipstatin produced by Streptomyces toxytricini) is an inhibitor of pancreatic and gastric lipase, reducing absorption of dietary fat. Orlistat was originally developed as an anti- 
obesity drug (Xenical $\left.{ }^{\mathrm{TM}}\right)$. Its efficacy was confirmed in a study of obese subjects with type 2 diabetes, in whom administration of orlistat combined with lifestyle intervention resulted in greater weight loss and better glycemic control than lifestyle changes alone (7). Orlistat is also an irreversible inhibitor of FASN (8), and several experimental studies demonstrated that through this mechanism, this agent displayed anticancer activity against: prostate tumor xenografts in mice, melanoma cell line B16F10, breast cancer cell lines, and gastric tumor-bearing mice (9-12). To the best of our knowledge, the effects of orlistat on PANC-1 human pancreatic cancer cells have not been studied thus far. Therefore, the aim of this study was to analyze the anticancer activity of orlistat against PANC-1.

\section{Materials and Methods}

Cell culture. PANC-1 Human pancreatic cancer cell line obtained from Sigma-Aldrich (Poznan, Poland) was cultured in low glucose Dulbecco'smodified Eagle's medium (DMEM) supplemented with heat-inactivated fetal bovine serum (to a final concentration of $10 \%)$, penicillin (100 units $/ \mathrm{ml})$ and streptomycin $(100 \mu \mathrm{g} / \mathrm{ml})$. The cells were maintained at $37^{\circ} \mathrm{C}$, under a humidified atmosphere with $5 \% \mathrm{CO}_{2}$.

Treatment with orlistat. Orlistat (Sigma) was dissolved in dimethyl sulfoxide (DMSO). PANC-1 cells were cultured for $72 \mathrm{~h}$ with different concentrations of orlistat (with final concentration of DMSO g $0.25 \%, \mathrm{v} / \mathrm{v}$ ) or solely with DMSO (at final concentration of $0.25 \%, v / v)$ as a control. Moreover, in order to verify if the study drug really acted as a FASN inhibitor, some PANC-1 cells were preincubated with $50 \mu \mathrm{M}$ palmitic acid for $30 \mathrm{~min}$, and then cultured with palmitate with orlistat for $72 \mathrm{~h}$.

Cell imaging and counting. Cultured cells were photographed with a digital camera coupled with Nikon TMS inverted microscope (Minato, Tokyo, Japan). The cells were then trypsinized and counted with the aid of Penta Square chambers (Medlab Products, Raszyn, Poland).

Analysis of cell viability. After 72-h culture with different concentrations of orlistat (or DMSO as a vehicle control) on 96-well plates, the cell proliferation rate was determined with MTT assay (thiazolyl blue tetrazolium bromide) (Sigma) in line with the manufacturer's instruction. Absorbance was measured at $570 \mathrm{~nm}$, with BioTek Synergy HT microplate reader (BioTek Instruments Winooski, VT, USA).

Measurement of apoptosis. After 72-h incubation, apoptosis was measured with EnzChek Caspase-3 Assay Kit \#1 (Thermo Fisher Scientific, Waltham, MA, USA), in line with the manufacturer's instruction. Briefly, orlistat-treated and control cells were harvested, washed with phosphate-buffered saline and lysed in Cell Lysis Buffer. After centrifugation, supernatants were transferred to individual microplate wells. Cell Lysis Buffer was used as noenzyme control to determine background fluorescence and benzyloxycarbonyl 7-amino-4-methylcoumarin-derived substrate was added to each sample as a substrate. Proteolytic cleavage of the substrate results in the release of fluorescent product. Fluorescence intensity, proportional to the activity of caspase- 3 in pretreated cells was measured at $360 / 460 \mathrm{~nm}$ excitation/emission, with BioTek Synergy HT microplate reader.

Determination of $m R N A$ levels of FASN and sterol regulatory element-binding protein 1 (SREBP1) by reverse transcription polymerase chain reaction $(R T-P C R)$. Total RNA was isolated from PANC-1 cells using GeneElute Total RNA Purification Kit (SigmaAldrich). The RNA concentration was determined based on the absorbance at $260 \mathrm{~nm}$ (Beckman DU-640 Spectrophotometer; Beckman-Coulter, Brea, CA, USA). Subsequently, $1 \mu \mathrm{g}$ of isolated RNA was reverse-transcribed using RevertAid First Strand cDNA Synthesis Kit (Thermo Fisher Scientific), in line with the manufacturer's instruction. Real-time PCR was conducted with CFX96 Real-Time PCR Detection System (Bio-Rad, Hercules, CA, USA), using iQSYBR Green Supermix (Bio-Rad) and the following pairs of specific forward $(\mathrm{F})$ and reverse $(\mathrm{R})$ primers: FASN FCGGAGGCATCAACCCAGATT, R-CTGTAGCCCACGAGTGT CTC; SREBP1 F-CGGAACCATCTTGGCAACA, R-GCCG GTTGATAGGCAGCTT; $\beta$-actin (ACTB) F-TGTCACCAACT GGGACGATA, and R-GGGGTGTTGAAGGTCTCAAA. Relative mRNA levels for the analyzed genes were quantified using comparative $2^{-\Delta \Delta \mathrm{CT}}$ method against $\beta$-actin as a reference gene.

Determination of lipogenesis rate in PANC-1 cells. Lipogenesis rate was determined based on the incorporation of tritium from ${ }^{3} \mathrm{H}_{2} \mathrm{O}(2$ $\mathrm{mCi} / \mathrm{ml}$ ) into fatty acids during 24-h incubation of PANC-1 cells, as described by Gibbons et al. (13). Lipogenesis was stopped by a 15 -min incubation with $1.5 \mathrm{ml} 5 \mathrm{~N} \mathrm{KOH}$, and then, after adding $1.5 \mathrm{ml}$ of $95 \%$ ethanol, the samples were again incubated for $2 \mathrm{~h}$. After cooling, the samples were acidified with $1.5 \mathrm{ml}$ of sulfuric acid, followed by extraction of lipids with petroleum ether. The petroleum ether layer was washed twice with $5 \mathrm{ml}$ of water. Radioactivity of the lipid fraction was determined with a Beckman LS 6000 IC liquid scintillation counter (Beckman-Coulter).

FASN activity assay. Activity of FASN was measured spectrophotometrically based on the rate of NADPH oxidation (14). Briefly, PANC-1 cells were lysed in a lysis buffer $[20 \mathrm{mM}$ Tris- $\mathrm{HCl}$ (pH 7.8), 0.2\% Triton X-100]. The lysates were centrifuged, and protein content in supernatants was determined with Lowry's method. Supernatants were incubated at $37^{\circ} \mathrm{C}$ with $0.1 \mathrm{M}$ potassium phosphate (pH 7.0), 0.2 M EDTA, $1 \mathrm{mM}$ dithiothreitol, $0.15 \mathrm{mM}$ NADPH, $25 \mu \mathrm{M}$ malonyl-CoA and $100 \mu \mathrm{M}$ acetyl-CoA. FASN activity was determined with Beckman DU-640 Spectrophotometer, based on a decrease in absorption at $340 \mathrm{~nm}$ resulting from NADPH oxidation. The results were expressed in $\mathrm{nmol} / \mathrm{min} / \mathrm{mg}$ of protein.

Statistical analysis. The results are presented as the mean \pm SEM. Statistical significance of intergroup differences was verified with one-way analysis of variance (ANOVA) with Holm-Sidak post-hoc test. The results were considered significant at values of $p<0.05$.

\section{Results}

PANC-1 cells were cultured for 4 days. A gradual increase in both FASN mRNA level and FASN activity was observed during the incubation, up to $200 \%$ and $400 \%$ that of respective baseline levels on day 4 (Figure $1 \mathrm{~A}$ and $\mathrm{B}$ ). The 

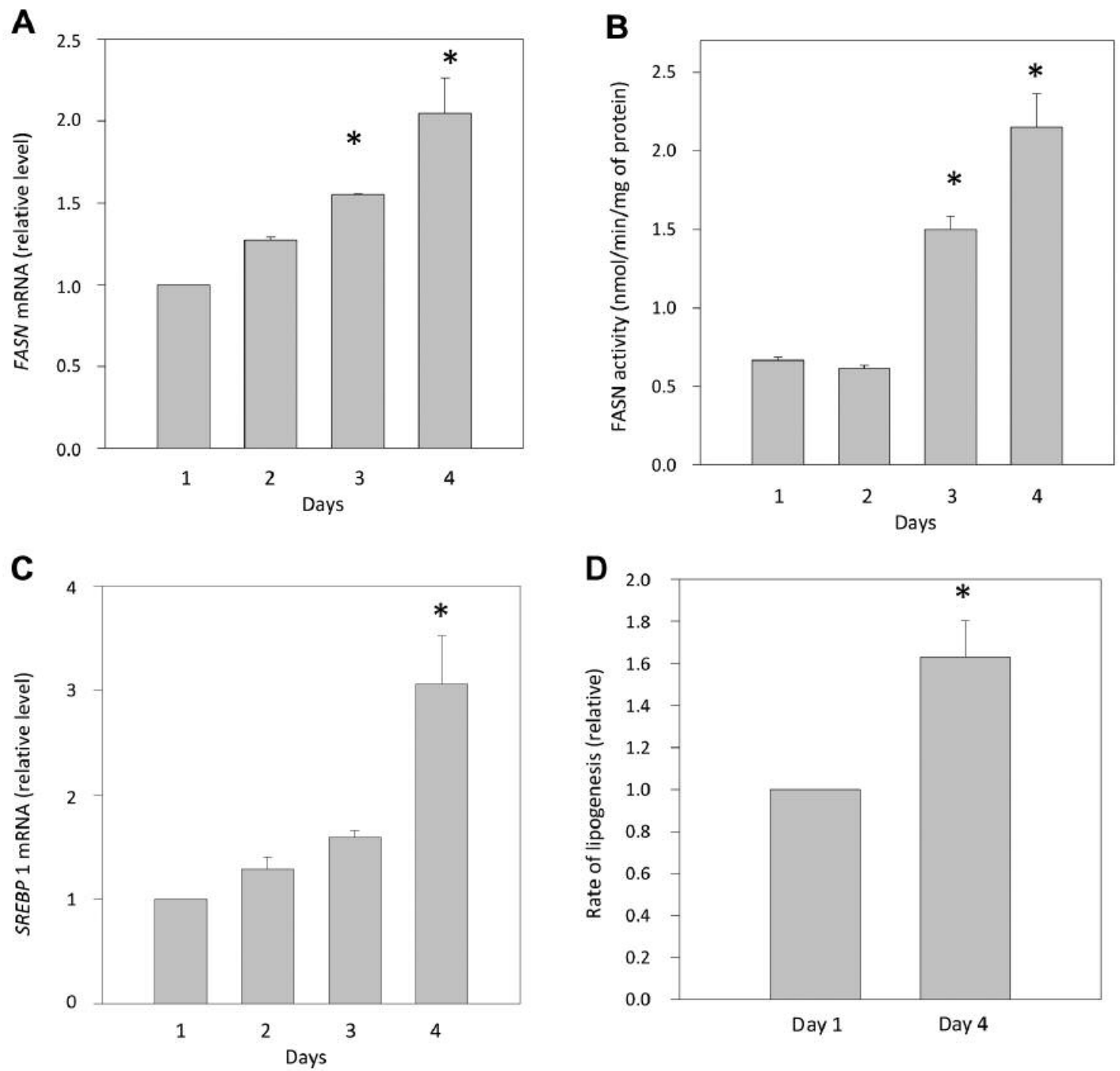

Figure 1. Fatty acid synthase (FASN) mRNA level (A) and activity (B), and sterol regulatory element-binding protein 1 (SREBP1) mRNA level (C) in PANC-1 cells cultured for 4 consecutive days. D: The rate of fatty acid biosynthesis on the first and fourth day of culture. The results originate from at least three independent experiments, data are the mean \pm SEM. *Significantly different from the value on the first day of culture at $p<0.01$.

increase in FASN mRNA level was associated with an increase in mRNA level for $S R E B P 1$, the main transcription factor regulating FASN expression (Figure 1C). The rate of fatty acid biosynthesis on day 4 was approximately $50 \%$ higher than at baseline (day 1; Figure 1 D). Treatment of PANC-1 cells with orlistat for $72 \mathrm{~h}$ was reflected by a dosedependent decrease in the cell number and viability (Figure 2A-C). Viability of cells treated with $50 \mu \mathrm{M}$ orlistat corresponded to approximately $50 \%$ that of untreated cells. Furthermore, treatment with orlistat induced some morphological changes of PANC-1 cells, as shown by a larger proportion of cells with a spherical shape (Figure
2B). Moreover, orlistat stimulated a dose-dependent increase in caspase-3 activity in PANC-1 cultures (Figure 2D). Activity of caspase-3 in cultures treated with $50 \mu \mathrm{M}$ orlistat was approximately 3 -fold higher than in control cells. Finally, treatment with $50 \mu \mathrm{M}$ orlistat caused inhibition of fatty acid biosynthesis in PANC-1 cells (Figure 2E). In order to verify if the antiproliferative effect of orlistat resulted from depletion of the main FASN product, palmitate, PANC-1 cells were incubated with both orlistat and a surplus of palmitate. As shown in Figure 3, the addition of palmitate to PANC- 1 cultures eliminated the antiproliferative effect of orlistat. 


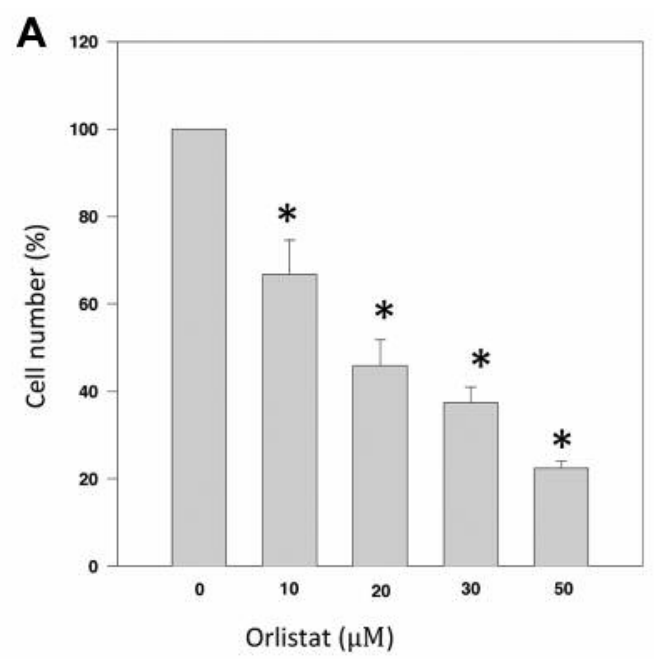



Control

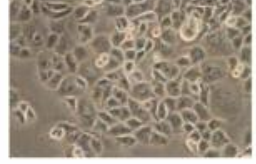

$10 \mu \mathrm{M}$

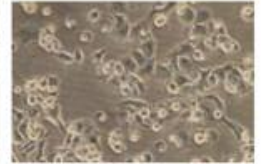

$20 \mu \mathrm{M}$

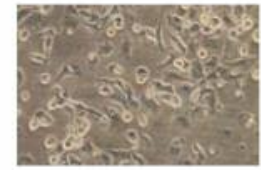

$30 \mu \mathrm{M}$

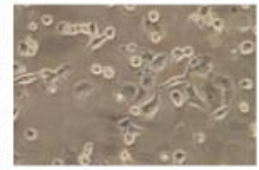

$50 \mu \mathrm{M}$

Orlistat


E

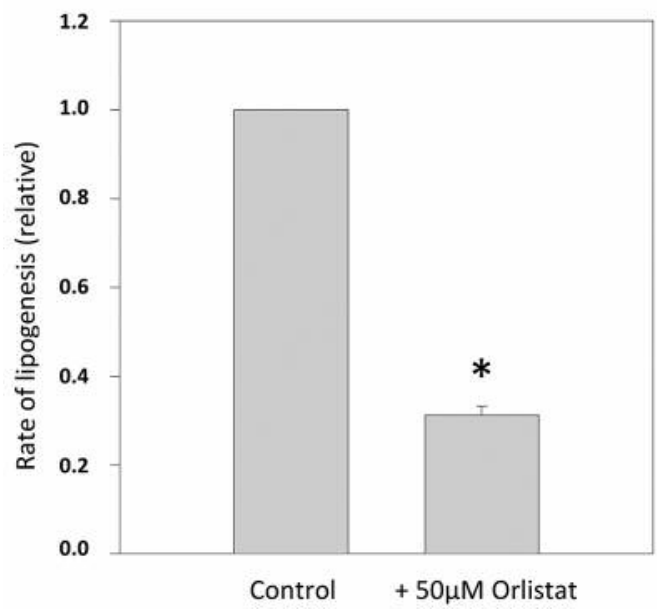

Figure 2. Influence of increasing orlistat concentration on PANC-1 cell number $(A)$, morphology $(B)$, viability $(C)$, apoptosis $(D)$ and lipogenesis rate (E) in cells cultured for $72 \mathrm{~h}$. Morphological changes were evaluated under a light microscope at $\times 100$ magnification. Cell counts were determined under a microscope with an aid of a hemocytometer. Cell viability was determined with an MTT assay. Apoptosis rate was measured based on caspase- 3 activity. The results originate from at least three independent experiments, data are the mean \pm SEM. *Significantly different from the control cell culture without orlistat at $p<0.01$. 
A

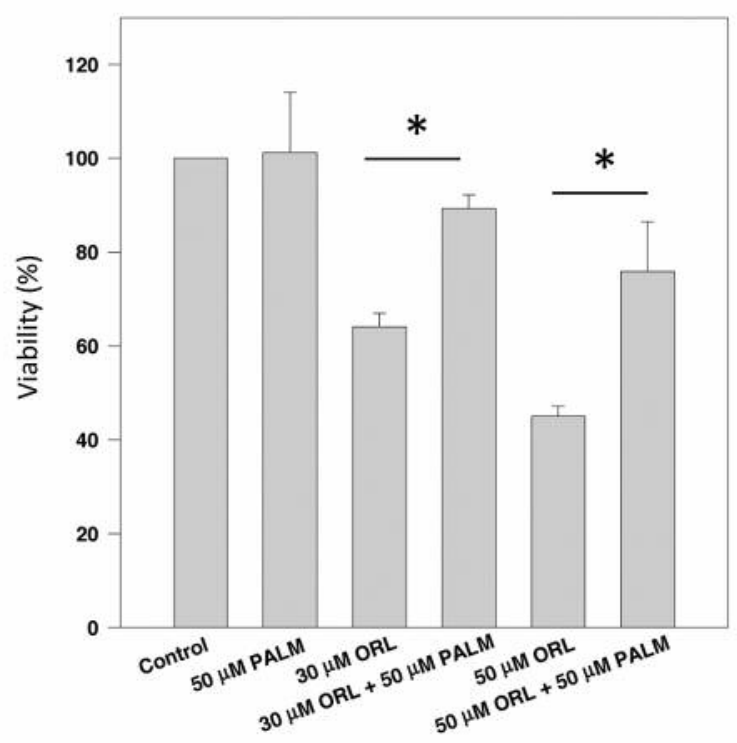

B

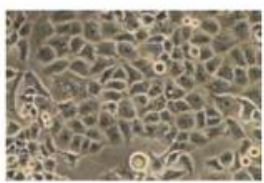

Control

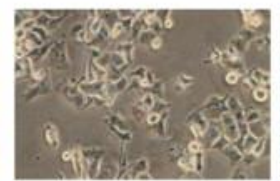

$30 \mu \mathrm{M}$ ORL

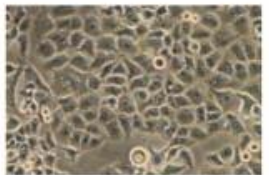

$50 \mu \mathrm{M}$ PALM

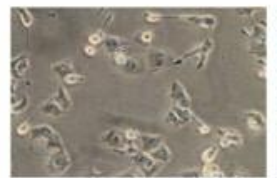

$50 \mu \mathrm{M}$ ORL

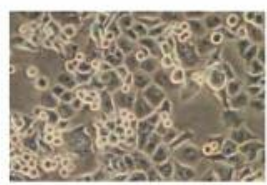

$30 \mu \mathrm{M}$ ORL + $50 \mu \mathrm{M}$ PALM

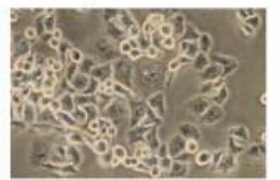

$50 \mu \mathrm{M}$ ORL +

$50 \mu$ M PALM

Figure 3. Reversal of the antiproliferative effect of orlistat (ORL) in PANC-1 cells cultured for $72 \mathrm{~h}$ with $50 \mu M$ palmitate (PALM). The results originate from at least three independent experiments, data are the mean \pm SEM. *Significantly different at $p<0.01$.

\section{Discussion}

This study showed that proliferation of PANC-1 was associated with a significant increase in FASN expression. This observation is consistent with the results of previous studies $(5,15,16)$ that also documented overexpression of FASN in pancreatic tumor tissue. The increase in FASN expression seems to result from up-regulation of SREBPI transcription factor, the main regulator of fatty acid synthesis $(17,18)$. Indeed, overexpression of SREBP1 has already been observed in pancreatic cancer tissue (19). Increased expression of FASN results in enhanced production of fatty acids that are necessary for both synthesis of cell membrane lipids and proliferation of cancer cells; furthermore, overexpression of FASN contributes to palmitoylation of proteins involved in carcinogenesis (1). Based on this evidence, FASN seems to be an attractive target for pancreatic cancer pharmacotherapy. Even more importantly, overexpression of this factor was shown to be associated with resistance of pancreatic cancer cells to gemcitabine and radiotherapy (5).

In this study, we tested orlistat, an agent that has already been authorized for pharmacotherapy of obesity and type 2 diabetes mellitus, as a potential inhibitor of FASN (20). We showed that incubation with orlistat resulted in reduced activity of FASN and reduction of lipogenesis in pancreatic cancer cells. These changes were associated with a decrease in PANC-1 proliferation and enhanced activity of caspase-3, a marker of apoptosis (21). These findings suggest that orlistat may induce apoptosis of PANC-1 cells. Recently, Harris et al. demonstrated that treatment with other FASN inhibitors, a plant-derived flavonoid, luteolin, and a synthetic compound, $\mathrm{C} 75$, reduced proliferation of MIA PaCa-2 pancreatic cancer cells (6). Similar effects were also observed for other two FASN inhibitors, cerulenin and irgasan, which also suppressed proliferation of MiaPaCa-2 cells (22). To the best of our knowledge, orlistat has not been studied as an inhibitor of pancreatic cancer cell proliferation thus far. Consequently, our study is the first to demonstrate antiproliferative properties of this agent.

Importantly, other than the previously mentioned FASN inhibitors, orlistat is already authorized for treatment of obesity and type 2 diabetes mellitus (20), and its antiproliferative potential has been documented in prostate cancer cells $(9,23,24)$, squamous cell carcinoma of the tongue (25), glioblastoma cells (26), ovarian cancer cell line SKOV3 (27), NUGC-3 gastric cancer cells (12), human colorectal carcinoma-bearing mice (28), myeloma cells (29), liposarcoma cells (30), T-cell lymphoma (31), retinoblastoma (32), breast cancer cells (10) and mouse melanoma B16-F10 cells (33). However, it was unclear if these antiproliferative effects resulted from depletion of palmitate, the main product of FASN. Our findings presented here imply that this is indeed the case. Firstly, incubation with orlistat contributed to a decrease in fatty acid synthesis in PANC-1 cells. Secondly, the antiproliferative effect of orlistat was abolished 
by addition of palmitate (a product of FASN) to the pancreatic cancer cell culture (Figure 3). Inhibition of proliferation and induction of apoptosis were therefore likely associated with depletion of fatty acids necessary for the synthesis of cell membrane lipids. Taking into account the potential application of orlistat in pharmacotherapy of pancreatic cancer, it should be remembered that antiproliferative properties of this agent may be modulated by the blood (and perhaps also tissue) concentration of palmitate.

Aside from FASN inhibition, orlistat was also postulated to exert its antiproliferative effect via other mechanisms, such as induction of apoptosis, or reduction of proliferation rate due to direct toxicity and stimulation of intracellular accumulation of reactive oxygen species (34). However, our findings suggest that in the case of pancreatic cancer cells, reduced proliferation is a consequence of orlistat-mediated inhibition of FASN.

Potential application of orlistat as a systemic therapy for pancreatic cancer may be substantially limited due to the low cell membrane permeability of this agent, and its poor water solubility (35), oral bioavailability and metabolic stability (36). However, these limitations can probably be overcome, since several orlistat analogs have been synthesized recently $(37,38)$. Hopefully, at least one of the novel orlistat analogs will satisfy the criteria for use as a systemic therapy against pancreatic cancer.

In conclusion, this study showed that overexpression of FASN gene resulted in a significant increase in PANC-1 proliferation rate. However, inhibition of FASN by orlistat caused a decrease in proliferation and stimulated apoptosis of PANC-1 cells. These findings imply that orlistat may exert an anticancer effect in human pancreatic cancer cells (PANC1), similar to that observed in other cancer cell lines. Consequently, orlistat analogs with good oral bioavailability may find application in pharmacotherapy of pancreatic cancer.

\section{Acknowledgements}

This work was supported by grants no. ST-41 and ST-40.

\section{References}

1 Swierczynski J, Hebanowska A and Sledzinski T: Role of abnormal lipid metabolism in development, progression, diagnosis and therapy of pancreatic cancer. World $\mathbf{J}$ Gastroenterol 20: 2279-2303, 2014.

2 Warburg O: The Metabolism of Tumors. Constable, London, 1930.

3 Cruz PM, Mo H, McConathy WJ, Sabnis N and Lacko AG: The role of cholesterol metabolism and cholesterol transport in carcinogenesis: a review of scientific findings, relevant to future cancer therapeutics. Front Pharmacol 25: 119, 2013.
4 Kuhajda FP, Jenner K, Wood FD, Hennigar RA, Jacobs LB, Dick JD and Pasternack GR: Fatty acid synthesis: a potential selective target for antineoplastic therapy. Proc Natl Acad Sci SA 91: 6379-6383, 1994.

5 Yang Y, Liu H, Li Z, Zhao Z, Yip-Schneider M and Fan Q, Schmidt CM, Chiorean EG, Xie J, Cheng L, Chen JH and Zhang JT: Role of fatty acid synthase in gemcitabine and radiation resistance of pancreatic cancers. Int J Biochem Mol Biol 2: 8998, 2011.

6 Harris DM, Li L, Chen M, Lagunero FT, Go VL and Boros LG: Diverse mechanisms of growth inhibition by luteolin, resveratrol, and quercetin in MIA PaCa- 2 cells: a comparative glucose tracer study with the fatty acid synthase inhibitor C75. Metabolomics 8: 201-210, 2012.

7 Aldekhail NM, Logue J, McLoone P and Morrison DS: Effect of orlistat on glycaemic control in overweight and obese patients with type 2 diabetes mellitus: a systematic review and metaanalysis of randomized controlled trials. Obes Rev 16: 10711080, 2015.

8 Pemble CW, Johnson LC, Kridel SJ and Lowther WT: Crystal structure of the thioesterase domain of human fatty acid synthase inhibited by Orlistat. Nat Struct Mol Biol 14: 704-709, 2007.

9 Kridel SJ, Axelrod F, Rozenkrantz N and Smith JW: Orlistat is a novel inhibitor of fatty acid synthase with antitumor activity. Cancer Res 64: 2070-2075, 2004.

10 Menendez JA, Vellon L and Lupu R: Antitumoral actions of the anti-obesity drug orlistat $\left(\mathrm{Xenical}^{\mathrm{TM}}\right)$ in breast cancer cells: blockade of cell cycle progression, promotion of apoptotic cell death and PEA3-mediated transcriptional repression of HER2/NEU (ERBB-2) oncogene. Ann Oncol 16: 1253-1267, 2005.

11 Carvalho MA, Zecchin KG, Seguin F, Bastos DC, Agostini M, Rangel AL, Veiga SS, Raposo HF, Oliveira HC, Loda M, Coletta RD and Graner E: Fatty acid synthase inhibition with orlistat promotes apoptosis and reduces cell growth and lymph node metastasis in a mouse melanoma model. Int J Cancer 123: 25572565, 2008.

12 Dowling S, Cox J and Cenedella RJ: Inhibition of fatty acid synthase by Orlistat accelerates gastric tumor cell apoptosis in culture and increases survival rates in gastric tumor bearing mice in vivo. Lipids 44: 489-498, 2009.

13 Gibbons GF, Khurana R, Odwell A and Seelaender MC: Lipid balance in HepG2 cells: active synthesis and impaired mobilization. J Lipid Res 35: 1801-1808, 1994.

14 Swierczynski J, Goyke E, Wach L, Pankiewicz A, Kochan Z, Adamonis W, Sledzinski Z and Aleksandrowicz Z: Comparative study of the lipogenic potential of human and rat adipose tissue. Metabolism 49: 594-599, 2000.

15 Alo PL, Amini M, Piro F, Pizzuti L, Sebastiani V, Botti C, Murari R, Zotti G, Di Tondo U: Immunohistochemical expression and prognostic significance of fatty acid synthase in pancreatic carcinoma. Anticancer Res 27: 2523-2527, 2007.

16 Witkiewicz AK, Nguyen KH, Dasgupta A, Kennedy EP, Yeo CJ, Lisanti MP and Brody JR: Co-expression of fatty acid synthase and caveolin-1 in pancreatic ductal adenocarcinoma: implications for tumor progression and clinical outcome. Cell Cycle 7: 3021-3025, 2008.

17 Dettlaff-Pokora A and Sledzinski T and Swierczynski J: UpRegulation of Mttp and Apob gene expression in rat liver is related to post-lipectomy hypertriglyceridemia. Cell Physiol Biochem 36: 1767-1777, 2015. 
18 Horton JD, Goldstein JL and Brown MS: SREBPs: activators of the complete program of cholesterol and fatty acid synthesis in the liver. J Clin Invest 109: 1125-1131, 2002.

19 Sun Y, He W, Luo M, Zhou Y, Chang G, Ren W, Wu K, Li X, Shen J, Zhao X and Hu Y: SREBP1 regulates tumorigenesis and prognosis of pancreatic cancer through targeting lipid metabolism. Tumour Biol 36: 4133-4141, 2015.

20 Narayanaswami V and Dwoskin LP: Obesity: Current and potential pharmacotherapeutics and targets. Pharmacol Ther 170: 116-147, 2017.

21 Villa P, Kaufmann SH and Earnshaw WC: Caspases and caspase inhibitors. Trends Biochem Sci 22: 388-393, 1997.

22 Nishi K, Suzuki K, Sawamoto J, Tokizawa Y, Iwase Y, Yumita $\mathrm{N}$ and Ikeda $\mathrm{T}$ : Inhibition of fatty acid synthesis induces apoptosis of human pancreatic cancer cells. Anticancer Res 36: 4655-4660, 2016.

23 Sadowski MC, Pouwer RH, Gunter JH, Lubik AA, Quinn RJ and Nelson CC: The fatty acid synthase inhibitor triclosan: repurposing an anti-microbial agent for targeting prostate cancer. Oncotarget 5: 9362-9381, 2014

24 Yoshii Y, Furukawa T, Oyama N, Hasegawa Y, Kiyono Y, Nishii R, Waki A, Tsuji AB, Sogawa C, Wakizaka H, Fukumura T, Yoshii H, Fujibayashi Y, Lewis JS and Saga T: Fatty acid synthase is a key target in multiple essential tumor functions of prostate cancer: uptake of radiolabeled acetate as a predictor of the targeted therapy outcome. PLoS One 8: e64570, 2013.

25 Agostini M, Almeida LY, Bastos DC, Ortega RM, Moreira FS, Seguin F, Zecchin KG, Raposo HF, Oliveira HC, Amoedo ND, Salo T, Coletta RD and Graner E: The fatty acid synthase inhibitor orlistat reduces the growth and metastasis of orthotopic tongue oral squamous cell carcinomas. Mol Cancer Ther 13: 585-595, 2014.

26 Grube S, Dunisch P, Freitag D, Klausnitzer M, Sakr Y, Walter J, Kalff $\mathrm{R}$ and Ewald C: Overexpression of fatty acid synthase in human gliomas correlates with the WHO tumor grade and inhibition with orlistat reduces cell viability and triggers apoptosis. J Neurooncol 118: 277-287, 2014.

27 Huang HQ, Tang J, Zhou ST, Yi T, Peng HL, Shen GB, Xie N, Huang $\mathrm{K}$, Yang T, Wu JH, Huang CH, Wei YQ and Zhao X: Orlistat, a novel potent antitumor agent for ovarian cancer: proteomic analysis of ovarian cancer cells treated with Orlistat. Int J Oncol 41: 523-532, 2012.

28 Chuang HY, Chang YF and Hwang JJ: Antitumor effect of orlistat, a fatty acid synthase inhibitor, is via activation of caspase- 3 on human colorectal carcinoma-bearing animal. Biomed Pharmacother 65: 286-292, 2011.
29 Tirado-Velez JM and Joumady I, Saez-Benito A, CozarCastellano I and Perdomo G: Inhibition of fatty acid metabolism reduces human myeloma cells proliferation. PLoS One 7: e46484, 2011.

30 Olsen AM, Eisenberg BL, Kuemmerle NB, Flanagan AJ, Morganelli PM, Lombardo PS, Swinnen JV and Kinlaw WB: Fatty acid synthesis is a therapeutic target in human liposarcoma. Int J Oncol 36: 1309-1314, 2010.

31 Kant S, Kumar A and Singh SM: Fatty acid synthase inhibitor orlistat induces apoptosis in T-cell lymphoma: role of cell survival regulatory molecules. Biochim Biophys Acta 1820: 1764-1773, 2012.

32 Vandhana S, Coral K, Jayanthi U, Deepa PR and Krishnakumar S: Biochemical changes accompanying apoptotic cell death in retinoblastoma cancer cells treated with lipogenic enzyme inhibitors. Biochim Biophys Acta 1831: 1458-1466, 2013.

33 Seguin F, Carvalho MA, Bastos DC, Agostini M, Zecchin KG, Alvarez-Flores MP and Chudzinski-Tavassi AM, Coletta RD and Graner E: The fatty acid synthase inhibitor orlistat reduces experimental metastases and angiogenesis in B16-F10 melanomas. Br J Cancer 107: 977-987, 2012.

34 Azadbakht L, Jamali-Gojani Z and Heidari-Beni M: Anti-obesity drug orlistat (xenical) is a novel antitumor medication. Shiraz EMedical J 16(1): e26242, 2015.

35 Hoover HS, Blankman JL, Niessen S and Cravatt BF: Selectivity of inhibitors of endocannabinoid biosynthesis evaluated by activity-based protein profiling. Bioorg Med Chem Lett 18: 5838-5841, 2008.

36 Zhi J, Melia AT, Funk C, Viger-Chougnet A and Hopfgartner G, Lausecker B, Wang K, Fulton JS, Gabriel L and Mulligan TE: Metabolic profiles of minimally absorbed orlistat in obese/ overweight volunteers. J Clin Pharmacol 36: 1006-1011, 1996.

37 Richardson RD, Ma G, Oyola Y, Zancanella M, Knowles LM, Cieplak P, Romo D and Smith JW: Synthesis of novel betalactone inhibitors of fatty acid synthase. J Med Chem 51: 52855296, 2008.

38 Zhang W, Richardson RD, Chamni S, Smith JW and Romo D: Beta-lactam congeners of orlistat as inhibitors of fatty acid synthase. Bioorg Med Chem Lett 18: 2491-2494, 2008.

Received June 7, 2017

Revised June 29, 2017

Accepted July 3, 2017 